\title{
In Vivo Assessment of Antihyperglycemic and Antihyperlipidemic Potential of Sesamum Indicum Oil in Streptozotocin Induced Diabetic Rats
}

\author{
Manoj Kumar ${ }^{1 *}$, Suresh Kumar ${ }^{2}$, Sunil Sharma ${ }^{3}$ and Neeru \\ Vasudeva ${ }^{4}$ \\ 1Department of Pharmaceutical Sciences, Guru Jambheshwar University of Science \\ and Technology, India
}

\section{Research Article \\ Volume 3 Issue 2}

Received Date: February 17, 2018

Published Date: March 16, 2018

${ }^{2}$ Laureate Institute of Pharmacy, Kathog, Kangra (Himachal Pradesh), India

3Department of Pharmaceutical Sciences, Guru Jambheshwar University of Science and Technology, India

4Department of Pharmaceutical Sciences, Guru Jambheshwar University of Science and Technology, India

*Corresponding author: Manoj Kumar, Department of Pharmaceutical Sciences, Guru Jambheshwar University of Science and Technology, Hisar, Haryana-125001, India, Tel: 9466044774; Email: manojmedal05@gmail.com

\section{Abstract}

Aims: In the present study the antihyperglycemic and antihyperlipidemic effects of oil from seeds of Sesamum indicum Linn. (SIO) were investigated. A streptozotocin-nicotinamide (STZ) rat model of hyperglycaemia was used to evaluate the antihyperglycemic and antihyperlipidemic properties of oil of linseed.

Materials and Methods: The body weight, oral glucose tolerance test and biochemical parameters viz. glucose level, insulin level, liver glycogen content, glycosylated hemoglobin and lipid profile parameters were estimated for all treated groups and compared against diabetic control group.

Results: SIO (500 mg/kg/day and $1000 \mathrm{mg} / \mathrm{kg} /$ day) in respective groups of diabetic animals administered for 28 days reduced the blood glucose level in streptozotocin-nicotinamide induced diabetic rats. There was significant increase in body weight, liver glycogen content, plasma insulin level and decrease in the blood glucose and glycosylated hemoglobin in test groups as compared to control group.

Conclusions: The findings demonstrate that SIO have excellent antihyperglycemic and antihyperlipidemic activities and thus have great potential as a source for natural health products.

Keywords: Streptozotocin; Sesamum indicum; Fixed oil; Diabetes 


\section{Diabetes and Obesity International Journal}

\section{Introduction}

Now a day herbal remedies have become the popular source of medicines due to lesser adverse reactions and various other reasons. There are thousands of plants used from last years for the treatment of various diseases [1]. Diabetes is growing with a high speed in India and has become a capital of the world which is affecting the all age group of people [2-4]. There were an estimated 40 million persons with diabetes in India in 2007 and this number is predicted to rise to almost 70 million people by 2025 according to Diabetes Atlas published by the International Diabetes Federation (IDF). The country with the largest number of diabetic people will be India by 2030. Due to these sheer numbers, the economic burden due to diabetes in India is amongst the highest in the world [5]. Diabetes is of mainly three type's viz., Type I, type II, and Gestational. Type II diabetes is the most common type, accounting for $90-95 \%$ of all diabetic cases. So the main concern for management of this type of diabetes is very essential. Some studies have suggested that essential oils may be useful in the treatment of type II diabetes mellitus and various oils have been used as therapeutic agents for years without any significant adverse health effects [6].

The oil has been widely used in the food industries from centuries. As long as we know, the effect of oil on the blood profiles in diabetic models has not been studied. In light of these findings, we carried out this study for the evaluation of antihyperglycemic, and antihyperlipidemic potential of oil of seeds of Sesamum indicum.

\section{Materials and Methods}

\section{Drugs and Chemicals}

The drugs and chemicals used in the study were glibenclamide (Torrent Pharmaceutical, Ahmadabad), streptozotocin, heparin (SRL, India), EDTA (Hi-media Lab. Pvt Ltd., Mumbai, India), Ellman's reagent (5,5'-dithiobis(2-nitro-benzoic acid); DTNB), sodium sulphate, methanol, pyridine, anthrone, thiourea, benzoic acid, sodium chloride (SD Fine Chem Ltd., Mumbai, India). All the chemicals used in the study were of analytical grade.

\section{Isolation of Oil}

The dried seeds of Sesamum indicum were purchased from oil and seed section of Chaudhary Charan Singh Haryana Agriculture University, Hisar, India. The seeds were crushed and oil was extracted with the help of Clevenger apparatus. The percentage yield of light yellow colored oil was found to be $45 \%$.

\section{Experimental Animals}

Healthy albino wistar rats (150-250 g) were procured from Disease Free Small Animal House, Lala Lajpat Rai University of Veterinary \& Animal Sciences, Hisar (Haryana). The rats were housed in (Polycarbonate cage size: $29 \times 22 \times 14 \mathrm{~cm}$ ) under laboratory standard conditions (25 $\pm 33^{\circ} \mathrm{C}: 35-60 \%$ humidity) with alternating light and dark cycle of $12 \mathrm{~h}$ each and were feed fed with a standard rat pellet diet (Hindustan Lever Ltd, Mumbai, India) and water ad libitum. The experimental protocol was approved by Institutional Animals Ethics Committee (IAEC) and animal care was taken as per the guidelines of Committee for the Purpose of Control and Supervision of Experiments on Animals (CPCSEA), Govt. of India (Registration No. 0436).

\section{Induction of Diabetes}

Type II diabetes mellitus (NIDDM) was induced in overnight fasted animals by a single intraperitoneal injection of $50 \mathrm{mg} / \mathrm{kg} \mathrm{STZ}$ in $0.1 \mathrm{M}$ citrate buffer (pH-4.5) in a volume of $1 \mathrm{ml} / \mathrm{kg}$ body weight 15 minute after the i.p. administration of $110 \mathrm{mg} / \mathrm{kg}$ nicotinamide. Diabetes was developed and stabilized over a period of 7 days. Diabetes was confirmed by the elevated blood glucose levels determined at $72 \mathrm{~h}$ and on 7th day after injection. Only rats confirmed with permanent NIDDM (Glucose level above $250 \mathrm{mg} / \mathrm{dl}$ ) were used in the study. Blood was collected by intraocular route [7].

\section{Experimental design}

Rats were divided into the following groups comprising six rats in each group after the induction and confirmation of diabetes.

\section{For acute antihyperglycemic model}

In the acute antihyperglycemic models the study was carried out for 4 hours to check whether the plant have some effect or not.

Group 1 Normal rats

Group 2 Diabetic control

Group 3 Diabetic animals were administered glibenclamide (0.6 mg/kg p.o)

Group 4 Diabetic animal were administered orally 500 $\mathrm{mg} / \mathrm{kg}$ of SIO

Group 5 Diabetic animal were administered orally 1000 $\mathrm{mg} / \mathrm{kg}$ of SIO

\section{For chronic antihyperglycemic model}

In the chronic antihyperglycemic models the study was carried out for 28 days to study the various parameters of the diabetes to confirm the antihyperglycemic activity of $\mathrm{SIO}$ in streptozotocin induced diabetes in rats. 


\section{Diabetes and Obesity International Journal}

Group 1 Normal rats

Group 2 Diabetic control

Group 3 Diabetic animals were administered glibenclamide (0.6 mg/kg p.o)

Group 4 Diabetic animal were administered orally 500 $\mathrm{mg} / \mathrm{kg}$ of SIO

Group 5 Diabetic animal were administered orally 1000 $\mathrm{mg} / \mathrm{kg}$ of SIO

\section{Sample Collection}

Blood sample: The $24 \mathrm{~h}$ fasted animals were sacrificed by cervical decapitation on 28th day of treatment. Trunk blood was collected in heparinized tubes and the plasma was obtained by centrifugation at $5000 \mathrm{rpm}$ for $5 \mathrm{~min}$. for the determination of biochemical parameters; glucose, insulin, cholesterol etc.

Estimation of plasma glucose and cholesterol: Plasma cholesterol and glucose level were measured by commercial supplied biological kit Erba Glucose Kit (GODPOD Method) and Erba Cholesterol Kit (CHOD-PAP Method) respectively using Chem 5 Plus- $V_{2}$ Auto-analyser (Erba Mannhein Germany) in plasma sample prepared as above. Glucose and cholesterol values were calculated as $\mathrm{mg} / \mathrm{dl}$ blood sample.

Estimation of glycosylated hemoglobin (Hb1Ac): Glycosylated hemoglobin was measured using commercial supplied biological kit (Erba Diagnostic) in plasma sample prepared as above using Chem 5 Plus $-\mathrm{V}_{2}$ Auto-analyser (Erba Mannhein Germany). Values are expressed as the percent of total hemoglobin.

Estimation of liver glycogen content: Liver glycogen estimation was done by the method as described by Seifter, et al. (1950) [8]. Immediately after excision from the animal, $1 \mathrm{~g}$ of the liver was dropped into a previously weighed test tube containing $3 \mathrm{ml}$ of $30 \%$ potassium hydroxide solution. The weight of the liver sample was determined. The tissue was then digested by heating the tube for $20 \mathrm{~min}$ in boiling water bath, and following this the digest was cooled, transferred quantitatively to a 50 $\mathrm{ml}$ volumetric flask, and diluted to the mark with water. The contents of the flask were then thoroughly mixed and a measured portion was then further diluted with water in a second volumetric flask so as to yield a solution of glycogen of $3-30 \mu \mathrm{g} / \mathrm{ml}$. Five $\mathrm{ml}$ aliquots of the final dilution were then pipette into Evelyn tube and the determination with anthrone was carried out. The amount of glycogen in the aliquot used was then calculated using the following equation:

$\mu \mathrm{g}$ of glycogen in aliquot $=100 \mathrm{U} / 1.11 \mathrm{SU}$ is the optical density of unknown solution. $S$ is the optical density of the $100 \mu \mathrm{g}$ glucose and 1.11 is the factor determined by Morris in 1948 for the conversion of the glucose to the glycogen.

Statistical analysis: The data for various biochemical parameters were evaluated by use of one-way ANOVA, followed by Dunnett's t-test using the software Sigma-Stat 3 . In all the tests, the criterion for statistical significance was $\mathrm{p}<0.05$.

\section{Results}

\section{Oral Glucose Tolerance Test}

The effect of SIO on plasma glucose level after glucose loading of $2 \mathrm{~g} / \mathrm{kg}$ body weight orally to the STZ diabetic rats is expressed in the table 2 . The blood glucose level rises to a maximum in $60 \mathrm{~min}$ after glucose loading. The oil (500 mg/kg and $1000 \mathrm{mg} / \mathrm{kg}$ body weight) treated groups showed a significant decrease in level of glucose as compared to control group. The oil treated group showed a marked fall in glucose level in $90 \mathrm{~min}$ to $120 \mathrm{~min}$ interval (Table 1).

\begin{tabular}{|c|c|c|c|c|c|c|}
\hline \multirow{2}{*}{ Treatment } & \multirow{2}{*}{ Dose } & \multicolumn{4}{|c|}{ Mean blood glucose concentration (mg/dl) \pm S.E.M } \\
\cline { 3 - 7 } & & $\mathbf{0 ~ m i n .}$ & $\mathbf{3 0} \mathbf{~ m i n}$. & $\mathbf{6 0} \mathbf{~ m i n}$. & $\mathbf{9 0} \mathbf{~ m i n .}$ & $\mathbf{1 2 0} \mathbf{~ m i n}$. \\
\hline Normal & --- & $80 \pm 2.6$ & $87 \pm 2.8$ & $90 \pm 3.8$ & $86 \pm 2.5$ & $83 \pm 2.7$ \\
\hline Diabetic control & ---- & $290 \pm 4.6$ & $390 \pm 5.3$ & $413.2 \pm 4.3$ & $360 \pm 2.7$ & $331 \pm 2.8$ \\
\hline SIO & $500 \mathrm{mg} / \mathrm{kg}$ & $325 \pm 2.9$ & $332 \pm 2.7$ & $350 \pm 3.2$ & $316 \pm 3.6^{*}$ & $286 \pm 4.1^{* *}$ \\
\hline SIO & $1000 \mathrm{mg} / \mathrm{kg}$ & $375 \pm 3.6$ & $384 \pm 4.5$ & $400 \pm 4.1$ & $359 \pm 3.4^{* *}$ & $300 \pm 3.3^{* *}$ \\
\hline
\end{tabular}

Table 1: Effect of Sesamum indicum oil in oral glucose tolerance test (OGTT).

Values are presented as mean \pm S.E.M.; $\mathrm{n}=6$ in each group. One way ANOVA followed by Dunnett's test ${ }^{*} \mathrm{p}<0.05 ;{ }^{* *} \mathrm{p}<$ 0.01 vs. diabetic control; SIO: Sesamum indicumoil 


\section{Diabetes and Obesity International Journal}

\section{Effect of SIO on STZ Diabetic Rats in Acute Study}

Administration of SIO at a dose $500 \mathrm{mg} / \mathrm{kg}$ body weight p.o. to STZ diabetic rats showed reduction in blood glucose level from $342 \mathrm{mg} / \mathrm{dl}$ to $277 \mathrm{mg} / \mathrm{dl}$ at $4^{\text {th }} \mathrm{h}$. When the dose was increased as $1000 \mathrm{mg} / \mathrm{kg}$ then the blood glucose level decreased from $334 \mathrm{mg} / \mathrm{dl}$ to $260 \mathrm{mg} / \mathrm{dl}$ which was found significant $(\mathrm{p}<0.01)$ when compared with diabetic control (Table 2).

\begin{tabular}{|c|c|c|c|c|c|c|}
\hline \multirow{2}{*}{ Treatment } & \multirow{2}{*}{ Dose } & \multicolumn{4}{|c|}{ Mean blood glucose concentration (mg/dl) \pm S.E.M) } \\
\cline { 2 - 6 } & & $\mathbf{0 ~ h}$ & $\mathbf{1 / 2} \mathbf{~ h}$ & $\mathbf{1 h}$ & $\mathbf{2 h}$ & $\mathbf{4 h}$ \\
\hline Normal & -- & $76 \pm 4.2$ & $80 \pm 3.2$ & $77 \pm 2.5$ & $82 \pm 4.1$ & $79 \pm 5.3$ \\
\hline Control & -- & $340.5 \pm 10.2$ & $342 \pm 11.3$ & $346 \pm 7.6$ & $341.0 \pm 6.7$ & $332.0 \pm 7.2$ \\
\hline SIO & $500 \mathrm{mg} / \mathrm{kg} \mathrm{p.o}$ & $352 \pm 5.7$ & $340.1 \pm 5.4$ & $309 \pm 4.5^{* *}$ & $303 \pm 3.4^{* *}$ & $287 \pm 3.6^{* *}$ \\
\hline SIO & $1000 \mathrm{mg} / \mathrm{kg} \mathrm{p.o}$ & $340 \pm 1.8$ & $313 \pm 1.9^{*}$ & $295 \pm 2.3^{* *}$ & $276 \pm 2.4^{* *}$ & $260 \pm 4.9^{* *}$ \\
\hline Glibenclamide & $0.6 \mathrm{mg} / \mathrm{kg} \mathrm{p.o}$ & $348 \pm 7.1$ & $328 \pm 3.2^{* *}$ & $288 \pm 6.4^{* *}$ & $260 \pm 5.2^{* *}$ & $249.0 \pm 6.8^{* *}$ \\
\hline
\end{tabular}

Table 2: Effect of Sesamum indicum oil in STZ induced diabetic rats in acute antihyperglycemic study.

Values are presented as mean \pm S.E.M; $n=6$ in each group. One way ANOVA followed by Dunnett's test ${ }^{a} p<0.01$ vs. normal; ${ }^{* *} \mathrm{p}<0.01$ vs. diabetic control; SIO: Sesamum indicumoil.

\section{Effect of SIO on STZ Diabetic Rats in Chronic Study}

In chronic study administration of SIO at the dose of $500 \mathrm{mg} / \mathrm{kg}$ body weight to STZ diabetic rats for 28 days showed a fall in plasma glucose level from $355 \mathrm{mg} / \mathrm{dl}$ to
$194 \mathrm{mg} / \mathrm{dl}$ on $28^{\text {th }}$ day when compared to 0 day value. SIO at the dose of $1000 \mathrm{mg} / \mathrm{kg}$ body weight showed a significant $(\mathrm{p}<0.01)$ fall in plasma glucose level from 365 $\mathrm{mg} / \mathrm{dl}$ to $156 \mathrm{mg} / \mathrm{dl}$ on $28^{\text {th }}$ day (Table 3 ).

\begin{tabular}{|c|c|c|c|c|c|c|}
\hline \multirow{2}{*}{ Treatment } & \multirow{2}{*}{ Dose } & \multicolumn{5}{|c|}{ Mean blood glucose concentration (mg/dl) \pm S.E.M } \\
\cline { 3 - 7 } & -- & $80 \pm 4.2$ & $79 \pm 3.2$ & $82 \pm 2.5$ & $85.5 \pm 4.1$ & $78 \pm 2.1$ \\
\hline Normal & -- & $380 \pm 7.3$ & $379 \pm 7.6$ & $384 \pm 6.7$ & $416 \pm 7.2$ & $410 \pm 5.4$ \\
\hline Control & $500 \mathrm{mg} / \mathrm{kg} \mathrm{p.o}$ & $346 \pm 7.4$ & $298 \pm 4.5^{* *}$ & $278 \pm 5.2^{* *}$ & $244 \pm 6.1^{* *}$ & $172 \pm 6.2^{* *}$ \\
\hline SIO & $1000 \mathrm{mg} / \mathrm{kg} \mathrm{p.o}$ & $372 \pm 5.2$ & $285 \pm 5.9^{* *}$ & $210 \pm 5.8^{* *}$ & $188 \pm 4.4^{* *}$ & $154 \pm 5.8^{* *}$ \\
\hline SIO & $0.6 \mathrm{mg} / \mathrm{kg} \mathrm{p.o}$ & $344 \pm 8.4$ & $259.2 \pm 7.7^{* *}$ & $166.3 \pm 4.9^{* *}$ & $140 \pm 2.6^{* *}$ & $124 \pm 1.8^{* *}$ \\
\hline Glibenclamide & & & & & & \\
\hline
\end{tabular}

Table 3: Effect of Sesamum indicum oil in STZ induced diabetic rats in chronic antihyperglycemic study.

Values are presented as mean \pm S.E.M; $n=6$ in each group. One way ANOVA followed by Dunnett's test ${ }^{a} p<0.01 \mathrm{vs}$. normal; ${ }^{* *}$ p $<0.01$ vs. diabetic control; SIO: Sesamum indicumoil

\section{Effect of SIO on Body Weight}

An increase in the body weight of normal rats was observed whereas the weight of diabetic control rats decrease from day 1 to day 28. SIO at the dose of
$500 \mathrm{mg} / \mathrm{kg}$ and $1000 \mathrm{mg} / \mathrm{kg}$ body weight respectively groups when administered to diabetic rats showed a significant change in body weight and it was increase as compared to the diabetic control group. $(\mathrm{p}<0.01)$ (Table 4). 


\section{Diabetes and Obesity International Journal}

\begin{tabular}{|c|c|c|c|c|c|}
\hline Sr. No. & Treatment & Dose & Initial Body Weight (g) & Final Body Weight (g) & Change in weight \\
\hline 1 & Normal & -- & $220 \pm 1.1$ & $240 \pm 1.5$ & 20 \\
\hline 2 & Diabetic Control & -- & $215 \pm 1.8$ & $194 \pm 2.0$ & $-21^{\mathrm{a}}$ \\
\hline 3 & SIO & $500 \mathrm{mg} / \mathrm{kg} \mathrm{p.o}$ & $248 \pm 2.2$ & $255 \pm 1.0$ & 5 \\
\hline 4 & SIO & $1000 \mathrm{mg} / \mathrm{kg} \mathrm{p.o}$ & $230 \pm 1.3$ & $250 \pm 1.4$ & $+20^{* *}$ \\
\hline 5 & Glibenclamide & $0.6 \mathrm{mg} / \mathrm{kg}$ p.o & $220 \pm 4.7$ & $250 \pm 1.8$ & $+30^{* *}$ \\
\hline
\end{tabular}

Table 4: Effect of Sesamum indicum oil in STZ induced diabetic rats on body weight.

Values are presented as mean \pm S.E.M; $\mathrm{n}=6$ in each group. One way ANOVA followed by Dunnett's test ap $<0.01 \mathrm{vs.}$ normal; ${ }^{* *} \mathrm{p}<0.01$ vs. diabetic control; SIO: Sesamum indicumoil.

\section{Effect of SIO on Insulin Level}

Table 5 shows the level of plasma insulin in the control and experimental groups of rats. Diabetic rats showed a significant decrease in plasma insulin compared with normal rats. Following dose of oral administration of SIO, plasma insulin level increased when compared to control rats (table 5).

\begin{tabular}{|c|c|c|c|c|}
\hline Treatment & Dose & HbA1c (\% of Hb) & Hepatic glycogen (mg/g wt of tissue) & Insulin (micro U/ml) \\
\hline Normal & -- & $6 \pm 1.4$ & $74 \pm 6.6$ & $14 \pm 2.1$ \\
\hline Diabetic Control & -- & $11.3 \pm 2.4^{\mathrm{a}}$ & $27 \pm 4.5^{\mathrm{a}}$ & $7.9 \pm 1.1^{\mathrm{a}}$ \\
\hline SIO & $500 \mathrm{mg} / \mathrm{kg}$ & $8.5 \pm 2.2$ & $46 \pm 1.8^{*}$ & $9.5 \pm 2.0$ \\
\hline SIO & $1000 \mathrm{mg} / \mathrm{kg}$ & $7.1 \pm 2.6^{* *}$ & $63 \pm 3.6^{* *}$ & $12.5 \pm 2.5^{*}$ \\
\hline Glibenclamide & $0.6 \mathrm{mg} / \mathrm{kg}$ & $7.0 \pm 0.7^{* *}$ & $66 \pm 2.8^{* *}$ & $11.9 \pm 1.0^{*}$ \\
\hline
\end{tabular}

Table 5: Effect of Sesamum indicum oil on glycosylated hemoglobin (HbA1c), hepatic glycogen and insulin in the study. Values are presented as mean \pm S.E.M; $n=6$ in each group. One way ANOVA followed by Dunnett's test ap $<0.01 \mathrm{vs.}$ normal; ${ }^{* *} \mathrm{p}<0.01$ vs. diabetic control; SIO: Sesamum indicumoil.

\section{Effect of SIO on Glycosylated Hemoglobin (HbA1c)}

The effect of SIO on HbA1c in STZ diabetic rats is shown in the table 6 . The level of glycosylated hemoglobin significantly increased $(\mathrm{p}<0.01)$ in diabetic rats as compared to normal control group. The diabetic rats when treated with SIO for 28 days showed a significant $(\mathrm{p}<0.01)$ decreased level of glycosylated $\mathrm{Hb}$ as compared to untreated diabetic group. The fall in glycosylated hemoglobin level was found to be dose dependent (table $5)$.

Effect of SIO on hepatic glycogen: The hepatic glycogen content in diabetic rats decreased sharply as compared to control animal (table 5). After chronic administration of SIO to diabetic rats, a significant increased $(p<0.01)$ liver glycogen content as compared to diabetic control group was observed.

Effect of SIO on Lipid profile: Table 6 shows the level of lipids in normal and tested animals. There was a significant decrease in the level of HDL-cholesterol and a significant increase in the levels of total cholesterol and triglycerides in diabetic rats when compared to normal rats. The administration of SIO reverse the level of lipids significantly $(\mathrm{p}<0.05$ and $\mathrm{p}<0.01)$.

\begin{tabular}{|c|c|c|c|c|}
\hline Treatment & Dose & Cholesterol (mg/dl) & Triglyceride (mg/dl) & HDL (mg/dl) \\
\hline Normal & -- & $85 \pm 1.5$ & $16 \pm 2.5$ & $66 \pm 1.9$ \\
\hline Diabetic Control & -- & $232 \pm 2.4^{\mathrm{a}}$ & $43 \pm 3.1^{\mathrm{a}}$ & $37.4 \pm 1.2^{\mathrm{a}}$ \\
\hline SIO & $500 \mathrm{mg} / \mathrm{kg}$ & $176 \pm 3.6^{* *}$ & $28 \pm 1.6^{* *}$ & $45 \pm 2.1$ \\
\hline SIO & $1000 \mathrm{mg} / \mathrm{kg}$ & $110 \pm 2.5^{* *}$ & $20 \pm 1.3^{* *}$ & $49 \pm 1.3^{*}$ \\
\hline Glibenclamide & $0.6 \mathrm{mg} / \mathrm{kg}$ & $138 \pm 1.8^{* *}$ & $14.4 \pm 1.2^{* *}$ & $53 \pm 1.8^{*}$ \\
\hline
\end{tabular}

Table 6: Effect of Sesamum indicum oil on Lipid profile.

Values are presented as mean \pm S.E.M; $n=6$ in each group. One way ANOVA followed by Dunnett's test ap $<0.01$ vs. normal; ${ }^{* *} \mathrm{p}<0.01$ vs. diabetic control; SIO: Sesamum indicum oil. 


\section{Diabetes and Obesity International Journal}

\section{Discussion}

The aim of the study was to evaluate the antidiabetic and antihyperlipidemic potential of the SIO in STZ induced diabetic rats. Diabetes mellitus causes a disturbance in the uptake of glucose as well as glucose metabolism. A dose of STZ as low as $50 \mathrm{mg} / \mathrm{kg}$ produces an incomplete destruction of pancreatic beta cells even though the rats become permanently diabetic [9-10]. After treatment with a low dose of STZ many beta cells survive and regeneration is also possible [11]. Hyperglycemia generates high levels of free radicals by autoxidation of glucose and protein glycation, and oxidative stress has been reported to be a positive factor of cardiovascular complications in STZ-induced diabetes mellitus [12]. Hyperglycemia is associated with the generation of reactive oxygen species (ROS) causing oxidative damage particularly to heart, kidney, eyes, nerves, liver, small and large vessels and gastrointestinal system [13]. The increased levels of plasma glucose in STZ-induced diabetic rats were lowered by SIO administration. The plasma glucose lowering activity was compared with glibenclamide, a standard hypoglycemic drug that stimulates insulin secretion from pancreatic beta cells [14]. From the results of the present study, it appears that still insulin producing cells are functioning and the stimulation of insulin release could be responsible for most of the metabolic effects. It may be suggested that the mechanism of action of SIO is similar to glibenclamide. The glucose lowering activity of SIO may be related to both pancreatic (enhancement of insulin secretion) and extra pancreatic (peripheral utilization of glucose) mechanism.

An increase in the level of glycosylated hemoglobin (HbA1c) in the diabetic control group of rats is due to the presence of large amount of blood glucose which reacts with hemoglobin to form glycosylated hemoglobin [15]. Oxidative stress increases due to the activation of transcription factors, advanced glycated end products (AGEs), and protein kinase C. If diabetes is persistent for long time, the glycosylated hemoglobin is found to increase [16]. The level of $\mathrm{HbA}_{1} \mathrm{C}$ was decreased after the administration of SIO $1000 \mathrm{mg} / \mathrm{kg}$ as compared to diabetic control group $(* * \mathrm{p}<0.01)$.

In STZ induced diabetes mellitus, the loss of body weight is caused by increase in muscle wasting and catabolism of fat and proteins [17]. Due to insulin deficiency protein content is decreased in muscular tissue by proteolysis [18]. A decrease in body weight was registered in case of STZ diabetic control group rats while in tested groups the weight loss was reversed. Fatty acid mobilisation from adipose tissue is sensitive to insulin. Insulin's most potent action is the suppression of adipose tissue lipolysis [19]. A rise in plasma insulin concentration of only $5 \mathrm{IU} / \mathrm{mL}$ inhibits lipolysis by $50 \%$, whereas a reduction in basal insulin levels result in a marked acceleration of lipolysis [20]. We demonstrated that SIO increased plasma insulin concentrations in diabetic rats. Insulin levels higher than those of the control group may result in inhibition of lipolysis and decreased plasma triglyceride and cholesterol levels. Some studies suggest that the antihyperglycemic action of traditional antidiabetic plant extracts may be due in part to decreased glucose absorption in vivo [21]. This mechanistic explanation may also apply to the actions of SIO in lowering the triglyceride and cholesterol level.

The conversion of glucose to glycogen in the liver cells is dependent on the extracellular glucose concentration and on the availability of insulin which stimulates glycogen synthesis over a wide range of glucose concentration [16]. Diabetes reduces activity of glycogen synthase thereby affecting the glycogen storage and synthesis in rat liver and skeletal muscle [22]. Oral administration of SIO $1000 \mathrm{mg} / \mathrm{kg}$ body weight significantly increased hepatic glycogen levels in STZ diabetic rats possibly because of the reactivation of the glycogen synthase system as a result of increased insulin secretion

In conclusion, the present study showed that oral administration of SIO has potential antidiabetic and antihyperlipidemic effect in STZ induced diabetic rats. This investigation reveals the potential of SIO for use as a natural oral agent with antihyperglycemic and antihyperlipidemic effects.

\section{References}

1. Velisek J, Mikulcova R, Mikova K, Woldie KS, Link J, Davídek J (1995) Chemometric investigation of mustard seed. Lebenson Wiss Technol 28(6): 620624.

2. Reddy TY, Reddy VR, Anbumozhi V (2003) Physiological Responses of Groundnut (Arachis hypogea L.) To Drought Stress and Its Amelioration: A Critical Review. Plant Growth Regulation 41(1): 7588.

3. Sharma KK, Anjaiah V (2000) An efficient method for the production of transgenic plants of peanut (Arachis hypoaeae L.) through Agrobacterium tumefaciens-mediated genetic transformation. Plant Sci 159: 7-19. 


\section{Diabetes and Obesity International Journal}

4. Mohan V, Sandeep S, Deepa R, Shah B, Varghese C (2007) Epidemiology of type 2 diabetes: Indian scenario. Indian J Med Res 125(3): 217-230.

5. Sicree R, Shaw J, Zimmet P (2006) Diabetes and impaired glucose tolerance. In: Gan D (Ed.), Diabetes Atlas. International Diabetes Federation. 3rd (Edn.), Belgium: International Diabetes Federation, pp: 15103.

6. Pandey A, Tripathi P, Pandey R, Srivatava R, Goswami $S$ (2011) Alternative therapies useful in the management of diabetes: A systematic review. J Pharm Bio allied Sci 3(4): 504-512.

7. Marudamuthu AS, Leelavinothan P (2008) Effect of pterostilbene on lipids and lipid profiles in Streptozotocin - Nicotinamide induced type 2 diabetes mellitus. J Appl Biomed 6: 31-37.

8. Seifter S, Dayton S, Molic B, Mutwzter E (1950) The estimation of glycogen with the anthrone reagent. In Archive Biochem 25(1): 191-200.

9. Okhawa H, Ohishi N, Yagi K (1979) Assay for lipid peroxides in animal tissue by thiobarbituric acid reaction. Anal Biochem 95(2): 351-358.

10. Aybar MJ, Riera ANS, Grau A, Sanchez SS (2001) Hypoglycemic effect of the water extract of Smallantus sonchifolius (yacon) leaves in normal and diabetic rats. J Ethnopharmacol 74: 125-132.

11. Gomes A, Vedasiromoni, JR, Das M, Sharma RM, Ganguly DK (2001) Anti-hyperglycaemic effect of black tea (Camellia sinensis) in rat. J Ethnopharmacol 27: 243-275.

12. Okutan H, Ozcelik N, Yilmaz HR, Uz E (2005) Effects of phenethyl ester on lipid peroxidation and anti oxidant enzymes in diabetic rat heart. Clin Biochem 38: 191196.

13. Tunali S, Yanardag R (2006) Effect of vanadyl sulfate on the status of lipid parameters and on stomach and spleen tissues of streptozotocin-induced diabetic rats. Pharmacol Res 53: 271-277.

14. Tian YM, Johnson G, Ashcroft JH (1998) Sulfonylureas enhance exocytosis from pancreatic b-cells by a mechanism that does not involve direct activation of protein kinase C. Diabetes 47: 1722-1726.

15. Chattopadhyay RR (1999) Possible mechanism of antihyperglycemic effect of Azadirachta indica leaf extract. J Ethanopharmacol 67: 373-376.

16. Sheela GC, Augusti K (1992) Antidiabetic effects of Sallyl cystine sulphoxide isolated from garlic Allium sativum Linn. Indian J Exp Biol 30: 523-526.

17. Chakravarti BK, Gupta S, Gambir SS, Gode KD (1981) Pancreatic betacell regeneration in rats by (-) epicatechin. The Lancet 2: 759-760.

18. Swanston-Flatt SK, Day C, Bailey CJ, Flatt PR (1990) Traditional plant treatments for diabetes studies in normal and streptozotocin diabetic mice. Diabetologia 33: 462-464.

19. Campbell PJ, Carlson MG, Hill JO, Nurjhan N (1992) Regulation of free fatty acid metabolism by insulin in humans: role of lipolysis and reesterification. Amer J Physiol 263: 1063-1069.

20. Bonadonna RC, Groop LC, Zych K, Shank M, DeFronzo RA (1990) Dose dependent effect of insulin on plasma free fatty acid turnover and oxidation in humans. Am J Physiol 259: 736-750.

21. Gallagher AM, Flatt PR, Duffy G, Abdel-Wahab YHA (2003) The effects of traditional antidiabetic plants on in vitro glucose diffusion. Nutrition Research 23(3): 413-424.

22. Kumar S, Kamboj J, Sharma S (2011) In vivo Antidiabetic and Anti-oxidant potential of Psoralea corylifolia seeds in Streptozotocin induced type- 2 diabetic rats. J health Sci 57(3): 1-11. 